\title{
Injury surveillance in accident and emergency departments: to sample or not to sample?
}

\author{
A Morrison, D H Stone
}

\begin{abstract}
Objectives-To establish whether injury surveillance based on sampling strategies is as valid as total patient surveillance. Methods-Canadian Hospitals Injury Reporting and Prevention Program (CHIRPP) data for 1996 were retrospectively analysed using five sampling frames. Proportions for key variables were calculated for each sample, then compared with the proportions for the total population of patients.

Results-Two of the five sampling frames produced statistically significant differences from the total population, which can be explained by seasonal variations. However, no significant differences were observed between the remaining three samples and the total population.

Conclusions-A well planned and executed sampling strategy can generate as valid data as total patient surveillance, obviating the need for data collection on every patient presenting with an injury or poisoning. In practice, however, systematic sampling can be difficult to implement and sustain, counterbalancing the economic advantages.

(Injury Prevention 1998;4:50-53)
\end{abstract}

Keywords: surveillance; sampling

Evidence suggests that injury surveillance in accident and emergency departments is a valuable and achievable objective. ${ }^{1-3}$ Such systems provide a proactive mechanism for routinely monitoring injury incidence, identifying risk factors, stimulating preventive programmes, and evaluating their effectiveness. ${ }^{3}$ However, the implementation and operation of such a system involves additional, often scarce, resources. In addition to the costs of system installation and maintenance, a considerable investment in personnel is usually required to collect, computerise, and analyse information. ${ }^{12}$

Although hospitals may be sampled to provide a representative data set across regions or nations, the majority of injury surveillance systems collect information on all patients presenting to the designated accident and emergency departments, ${ }^{14-7}$ making these systems relatively expensive. This paper examines whether it is necessary to include all patients in injury surveillance, or whether a sample offers a valid, and cheaper, alternative. Data collected during 1996 by the Canadian Hospitals Injury Reporting and Prevention Program (CHIRPP) system at the Royal Hospital for Sick Children in Glasgow were analysed retrospectively to examine the extent to which the use of various sampling frames would have resulted in representative samples, as reflected by the frequency distribution of selected key variables.

\section{Method}

CHIRPP is a computerised information system that collects data on all patients presenting with injuries or poisoning to accident and emergency departments. This system has been in operation at the Accident and Emergency Department, Royal Hospital for Sick Children, Yorkhill in Glasgow since 1993. ${ }^{1}$ During the calendar year 1996, 7940 CHIRPP forms were completed (over $90 \%$ of eligible patients). Several sampling frames were applied to these data. The sampling frames were largely arbitrary, although they had been identified as logistically possible: sample 1: every 10 th attendance $(n=794)$; sample 2 : every eighth day $(n=1032)$; sample 3: once a week (week day) $(n=1104)$; sample 4: once a week (weekend) $(n=1123)$; and sample 5: four months out of $12(n=2245)$.

Proportions for the following key variables were calculated: age, sex, injury type, injury location, activity at the time of injury, and the body part injured. For each sampling frame, the proportions for each sample were compared with the proportions for the total population of injured children recorded on CHIRPP. Confidence intervals were calculated, and differences between proportions examined using the common proportion and the standard error. ${ }^{7}$ The null hypothesis assumed no differences in the proportions between the samples. ${ }^{8}$

\section{Results}

Three statistically significant differences were found between the proportions generated by the sampling frames and the events observed in the total population of injured children (table 1). Significantly more children sustained 
Table 1 CHIRPP data 1996: sampling frames compared; values are per cent (95\% confidence interval)

\begin{tabular}{|c|c|c|c|c|c|c|}
\hline Variable & $\begin{array}{l}\text { Total population } \\
\text { of injured } \\
\text { children } \\
(n=7940)\end{array}$ & $\begin{array}{l}\text { Sample 1: every } \\
\text { 10th attendance } \\
(n=794)\end{array}$ & $\begin{array}{l}\text { Sample 2: every } \\
\text { eighth day } \\
(n=1032)\end{array}$ & $\begin{array}{l}\text { Sample 3: once a } \\
\text { week (weekday) } \\
(n=1104)\end{array}$ & $\begin{array}{l}\text { Sample 4: once a } \\
\text { week (weekend) } \\
(n=1123)\end{array}$ & $\begin{array}{l}\text { Sample 5: four } \\
\text { months (Fan } \\
\text { Apr, ful, Oct) } \\
(n=2245)\end{array}$ \\
\hline \multicolumn{7}{|l|}{ Age (years) } \\
\hline $0-4$ & 37 (36 to 38$)$ & $39(36$ to 42$)$ & 37 (34 to 40$)$ & 37 (34 to 40$)$ & 39 (36 to 42$)$ & 39 (37 to 41$)$ \\
\hline $5-9$ & $34(33$ to 35$)$ & $31(28$ to 34$)$ & $33(30$ to 36$)$ & $33(30$ to 36$)$ & $34(31$ to 37$)$ & $33(31$ to 35$)$ \\
\hline $10-14$ & $29(29$ to 30$)$ & $30(27$ to 33$)$ & $30(27$ to 33$)$ & $30(27$ to 33$)$ & $27(24$ to 30$)$ & $28(26$ to 30$)$ \\
\hline \multicolumn{7}{|l|}{ Sex } \\
\hline Male & $58(57$ to 59$)$ & 60 (57 to 63$)$ & $56(53$ to 59$)$ & 59 (56 to 62$)$ & $59(56$ to 62$)$ & $57(55$ to 59$)$ \\
\hline Female & $42(41$ to 43$)$ & 40 (37 to 43$)$ & $44(41$ to 47$)$ & $41(38$ to 44$)$ & $41(28$ to 44$)$ & $43(41$ to 45$)$ \\
\hline \multicolumn{7}{|l|}{ Injury type } \\
\hline Cut/laceration & $21(20$ to 22$)$ & $22(19$ to 25$)$ & $19(17$ to 21$)$ & $19(17$ to 21$)$ & $20(18$ to 22$)$ & 23 (21 to 25$)$ \\
\hline Haematoma/bruise & $19(18$ to 20$)$ & $16(14$ to 19$)$ & $20(18$ to 22$)$ & $19(17$ to 21$)$ & $19(17$ to 21$)$ & $17(15$ to 19$)$ \\
\hline Fracture & $13(12$ to 14$)$ & $11(10$ to 12$)$ & $11(9$ to 13$)$ & $13(11$ to 15$)$ & $11(9$ to 13$)$ & $13(12$ to 14$)$ \\
\hline Inflamation/oedema & $12(11$ to 13$)$ & $14(12$ to 16$)$ & 13 (11 to 15$)$ & $14(12$ to 16$)$ & 13 (11 to 15$)$ & $13(12$ to 14$)$ \\
\hline Sprain/strain & $12(11$ to 13$)$ & $11(10$ to 12$)$ & $11(9$ to 13$)$ & $10(8$ to 12$)$ & $12(10$ to 12$)$ & $12(11$ to 13$)$ \\
\hline \multicolumn{7}{|l|}{ Injury location } \\
\hline Own home & $42(41$ to 43$)$ & 42 (38 to 46$)$ & $42(39$ to 45$)$ & $44(41$ to 47$)$ & $46(43$ to 49$)$ & 45 (43 to 47$)$ \\
\hline Public footpath & $18(17$ to 19$)$ & $17(14$ to 20$)$ & $15(13$ to 17$)$ & $16(14$ to 18$)$ & $20(18$ to 22$)$ & $20(18$ to 22$)$ \\
\hline School playground & $8(7$ to 9$)$ & 7 (5 to 9$)$ & $9(7$ to 11$)$ & $9(7$ to 11$)$ & $0^{\star}$ & $3^{\star}(2$ to 4$)$ \\
\hline Other home & $6(5$ to 7$)$ & $6(4$ to 8$)$ & 6 (5 to 7$)$ & $5(4$ to 6$)$ & 6 (5 to 7) & 6 (5 to 7 ) \\
\hline Public playground & $6(5$ to 7$)$ & $6(4$ to 8$)$ & $6(5$ to 7$)$ & 5 (4 to 6$)$ & $8(6$ to 10$)$ & 7 (6 to 8 ) \\
\hline \multicolumn{7}{|l|}{ Activity } \\
\hline Playing & 67 (66 to 68$)$ & $68(65$ to 71$)$ & $64(61$ to 67$)$ & 66 (63 to 69$)$ & 70 (67 to 73$)$ & $73^{\star}(71$ to 75$)$ \\
\hline Walk/run/crawl & $16(15$ to 17$)$ & $14(12$ to 16$)$ & $16(14$ to 18$)$ & $16(14$ to 18$)$ & $14(12$ to 16$)$ & 15 (13 to 17$)$ \\
\hline Informal sport & $5(5$ to 5$)$ & 5 (3 to 7$)$ & $6(5$ to 7$)$ & 5 (4 to 6$)$ & 4 (3 to 5$)$ & 5 (4 to 6$)$ \\
\hline \multicolumn{7}{|l|}{ Body part injured } \\
\hline Head & 39 (38 to 40$)$ & 40 (36 to 44$)$ & 39 (36 to 42 ) & 40 (38 to 42$)$ & 39 (36 to 42$)$ & 38 (36 to 40$)$ \\
\hline Upper extremities & $35(34$ to 36$)$ & 38 (35 to 41$)$ & $35(32$ to 38$)$ & $36(34$ to 38$)$ & 35 (32 to 38$)$ & 35 (33 to 37$)$ \\
\hline Lower extremities & $21(20$ to 22$)$ & 19 (16 to 22$)$ & $21(19$ to 23$)$ & $21(19$ to 23$)$ & $21(19$ to 23$)$ & 23 (21 to 25$)$ \\
\hline
\end{tabular}

^Statistically significant difference from total population.

an injury while playing and significantly fewer sustained injuries in the school playground in the four month sample (sample 5) than in the total population. The third difference was observed between the weekend sample (sample 4) and the total population: the proportion occurring in the school playground was significantly higher in the total population. No significant differences were found between the other sampling frames (samples 1,2, and 3) and the total population.

\section{Discussion}

The significant differences observed in the proportions between two of the systematic sampling frames and the total population of injured children may be explained by seasonal variation. July (included in sample 5) encompasses the school holidays, when it is likely that there will be an increase in the number of injuries sustained while playing in and around the home and a decrease in the number of injuries sustained in the school playground. This is probably also true for the weekend sample (sample 4) with respect to injuries sustained in the school playground.

No other significant differences were found, suggesting that a well planned and executed sampling strategy, such as sampling every 10 th attendance or collecting data every eighth day, can generate data of equal quality to surveillance including all patients. The use of a systematic sampling strategy may relieve the pressure on both personnel and other resources at accident and emergency departments by obviating the need for data collection on every patient presenting with an injury or poisoning. Such sampling strategies would not affect the overall quality of information available on a medical record because the CHIRPP data collection sheet is completed separately from routine record keeping.
Systematic sampling is also economically attractive. Adopting a sampling strategy for the CHIRPP system in Glasgow would result in cost reductions of approximately $30 \%$. The costs of installing CHIRPP, staff training, and data analysis would remain the same. However, considerable savings would be made in the data collection, coding, and computerisation phases. Such a reduction in the costs of running an injury surveillance system may entice other public health organisations and agencies to investigate the possibilities of introducing such a system in their locality.

Nevertheless, in practice, systematic sampling may present logistical problems that counterbalance the economic attractions. Staff may forget to include every patient, or more seriously, select cases in a biased manner (according to perceived severity, for example). Other disadvantages include the inability of a sample to provide a comprehensive profile of injuries, especially unusual or densely clustered events, and the unsuitability of a sample based surveillance system for clinical purposes, such as audit or medicolegal review.

Of course, surveillance based on data collected from just one hospital (whether sampled or not) is a relatively poor alternative to a population based system. However, if as this study suggests, a systematic sampling strategy is not detrimental to the quality of data collected at any one hospital, the adoption of a systematic sampling strategy in a representative sample of hospitals in a locality may result in better quality epidemiological information than a single hospital collecting information on all injury events.

This paper has demonstrated that a systematic sampling strategy can generate as valid data on the pattern of injuries presenting to accident and emergency departments as total population surveillance. However, there are 
both advantages and disadvantages to adopting sampling strategies. Each department must assess whether sampling is appropriate depending on their available resources and information requirements.

We would like to thank $\mathrm{Mr}$ Doraiswamy, consultant at the Accident and Emergency Department, Royal Hospital for Sick Children (RHSC), Yorkhill and the department staff for their Thanks also go to the clinical audit team at RHSC for inputting and managing the data.

1 Stone DH, Doraiswamy NV. The Canadian Hospitals Injury Reporting and Prevention Program (CHIRPP) in the UK a pilot study. Inj Prev 1996;2:47-51.
2 Beattie TF. An accident and emergency based child accident surveillance system: is it possible? 7 Accid Emerg Med 1996;13:116-8.

3 Graitcer PL. The development of state and local injury surveillance systems. I Safety Res 1987;18:191-8.

4 Harrison J, Tyson D. Injury surveillance in Australia. Acta Paediatr Fpn 1993;35:171-8.

5 Rogmans WHJ, Mulder S. European home and leisure accident surveillance system: evaluation of activities undertaken in the frame of the EC-demonstration project. Amsterdam: Consumer Safety Unit, 1990.

6 Department of Trade and Industry. HASS / LASS reports. London: Consumer Safety Unit, Department of Trade and Industry, 1995.

7 Canadian Hospitals Injury Reporting and Prevention Program. CHIRPP News (monthly). Ottawa: Bureau

Bland M. An introduction to medical statistics. Oxford: Oxford Medical Publications, 1996.

\title{
ANOVA, $t$ tests, and linear regression
}

\author{
Robert W Platt
}

In the last issue, I discussed logistic regression and the structure of linear models when the response or outcome is binary. Binary outcomes can take on only two values, like dead/alive or boy/girl, as compared with continuous outcomes which can take on any value on a numeric scale, like blood pressure or weight. Now, let's take a step back and consider the various models and tests for continuous outcomes. The common theme in these methods is explaining variability in the response variable, and dividing the total variance of a statistic into variation that can be explained and random variation that cannot be explained.

The $t$ test is probably the simplest commonly used statistical procedure. To compare the mean of a continuous variable in two different populations, the difference between the two means divided by its standard deviation has a special distribution, known in this case as the " $t$ distribution". This relationship also allows construction of confidence intervals for the difference in means, and these provide information about the mean difference and its variability. When the difference between the two means (the between groups variability) is large relative to its standard deviation (the random variability) the $t$ test will be statistically significant.

What happens when we want to test if there is a difference in means among three or more groups? Analysis of variance, or ANOVA, generalizes the $t$ test to several groups. Since there are more than two groups being compared, we have to look at more than just mean differences. The method for testing the whether the mean level in all of the groups is the same follows a general pattern similar to that for the $t$ test. The variance between groups summarizes the part of the total variability in the measures that can be explained by the assumption that the measurements come from different populations. The ratio between this "between groups variance" and the total variance in the dataset is high when there is a significant difference. This will occur when the means of the groups are far apart and the variability within the groups is small. The appropriate test of statistical significance here is the F test, which compares the ratio of the two variances to values found in $\mathrm{F}$ distribution tables.

The general test in the ANOVA model tests the null hypothesis that all of the group means are equal. Rejecting this hypothesis means that we believe that at least one difference of two means is not zero; often, we are interested in a specific difference, or in finding out which of the differences is significantly different from zero. To do this requires a second step-one that compares individual means using a modified version of the $t$ test which can be done with a variety of common procedures.

Finally, consider the situation where, rather than dividing the population into groups, we wish to examine the association between a continuous outcome and a continuous variable (this can be thought of as an ANOVA where we have many different groups and these groups are ordered by the values of the continuous covariate). Here, we use linear regression, which associates the two variables through a $\beta$ coefficient. ${ }^{1}$ This can easily be generalized to multiple regression, where we consider several covariates at the same time to try to understand their joint relationship to the outcome.

The $t$ test can be thought of as a simple regression model with the covariate taking on only two values, and the ANOVA can also be viewed as a regression model with multiple covariates. More complicated ANOVA models can also be thought of in regression frameworks. The regression approach requires more work but it allows us to consider all these models in one unified framework and thus allows complete control of the comparisons made. Further, the calculation of the $\beta$ coefficients and standard errors for these coefficients allows us to use confidence intervals rather than relying on hypothesis tests as in the ANOVA. 
These three procedures are the main ways of dealing with the association of a continuous variable with continuous or categorical (grouping) covariates. The regression approach has many advantages, including the unified framework, the easy use of confidence intervals, and the option to manipulate the covariates, that usually make it the best choice.

1 Platt RW. Logistic regression and odds ratios. Inj Prev 1997;3:294.

Further reading

Neter J, Kutner M, Nachtsheim C, et al. Applied linear statistical models. 4th Ed. Chicago: Irwin, 1996.

\section{Right gun, next villain, please}

An essay on "the campaign to encourage responsible drinking has scored a steady decline in drunk driving accidents and deaths. Now it's time to address ourselves to the car commercials" (Robert Ramsay, Globe and Mail, April 1997).

\section{Skateboarding on danger list}

"Skateboarding has joined hang gliding and rock climbing as one of California's legally dangerous sports" (Herald, October 1997).

\section{Child pushed screen; fell to death}

"He put his two hands on the screen and it fell". Parents blamed the landlord for failing to childproof the floor level windows. "This is the only way to make windows safe", said Dr Barry Pless (Montreal Gazette, 1997).

\section{Injuries add to call for safe infant walkers}

"Doctors and consumer advocates have long sought to ban baby walkers because they cause more injuries than any other children's product. The government has tried to solve the problem through optional warning labels and public education campaigns, but a new study concludes these efforts are ineffective" (Susan Gilber, New York Times, 1997). 


\section{REGIONAL REPORTS}

\section{Southern Africa (and beyond) report}

I am constantly aware that most of my reports selfishly concentrate on happenings in Southern Africa. Occasionally, I am able to glean the odd item on what is happening further north from news reports, what little there is on the internet, or from that outstanding monthly, "BBC Africa". Rather than bore readers with poor excuses for this imbalance, may I rather reconfirm that I would welcome news (in any form whatsoever) related to childhood injury in Africa, and inclusion of which would allow this column to become more representative of the entire continent than it currently is. Those who are kind enough to submit news items will be personally acknowledged.

Having got that off my chest, I am thrilled to report on a fresh and exciting injury prevention campaign that has been hatched in Uganda, thanks to both support and input of local and international agencies. I am extremely grateful to Dr Olive Kobusingye, Director of the Injury Control Centre based at Makerere Medical School in Kampala, for providing me with the following information:

"Representatives from Ethiopia, Kenya, Uganda, Zambia, Zimbabwe, South Africa, and the World Health Organization (WHO) met on December 15-17 in Entebbe, Uganda at the joint WHO/Injury Control Centre Uganda (ICC-U) Working Group Meeting on Injury Prevention and Control in East and Southern Africa. Participants focused on the health sector issues of injury surveillance emergency medical systems, and health professional training in injury epidemiology and trauma care. A set of recommendations was formulated which has the potential to be a milestone for injury prevention in Africa.

The adoption of a standardized minimum data set for hospital based injury surveillance was discussed. A trauma registry form tested and used by the ICC-U will be presented to injury control workers in participating countries for input and development of a common format; it is hoped that this data set will form the core of a common trauma registry system in these countries. The single page trauma registry form includes ICD-9 categories of injury, a severity instrument (the Kampala score), victim and event information, and intentionality. Operate definitions for the registry have been written, and the form has already been tested in Uganda and Ethiopia. The trauma registry form is sufficient for base line injury measurements while at the same time keeping the form short and simple enough for a range of health workers to fill out".

Contact details for ICC-U: Dr Olive Kobusingye, Makerere Medical School, PO Box 7072, Kampala, Uganda (fax: +256 41 530022; e-mail: olive@imul.com).

DAVID BASS Department of Paediatric Surgery Red Cross War Memorial Children's Hospital, Rondebosch 7700, South Africa

Editor's note: While most Regional Reports have come from regular contributors-our team of Regional Editors-I am always delighted to receive contributions, regular or otherwise, from others, especially from parts of the world where we do not have Editorial Board members. Please send your contributions to the editor, Barry Pless.

\section{Pedestrian and bicyclist safety in New York City}

Pedestrian and bicyclist safety in New York City (NYC) has been in the news lately. Mayor Rudolph Giuliani has raised the ire of NYC residents by increasing the fine for jaywalking from $\$ 2$ to $\$ 50$, plus making a court appearance mandatory for paying fines for this offence. In addition, the mayor has recently announced that pedestrian barriers which separate pedestrians and vehicles at certain intersections will be kept up "indefinitely". Anyone who has walked or driven the streets of New York know that its pedestrians are among the most aggressive in the world. The scene from the Midnight Cowboy in which Dustin Hoffman screams to an incensed driver, "I'm walking here!" exaggerates the attitude of the New York pedestrian, but only a little.

Pedestrian and bicyclist injuries are a serious and sizeable problem in NYC city. There was a $23 \%$ increase in the number of pedestrians and bicyclists killed in motor vehicle crashes in NYC last year, from 249 in 1996 to 302 according to preliminary police statistics for 1997, 3700 hospitalizations annually, and an estimated 10000 pedestrians struck by motor vehicles but not hospitalized. Between 1994 and 1996 pedestrian deaths due to motor vehicles declined slightly from 223 to 213 . In this same period motor vehicle occupant deaths decreased more substantially from 207 to 169 . Despite the preponderance of pedestrian and bicyclist deaths, a study by Transportation Alternatives, a NYC watchdog group, found that most of the $\$ 400$ million of New York State and NYC funds earmarked for transportation safety in the next five years will go to improve the safety of vehicle occupants rather than the safety of pedestrians and bicyclists.

From a public health perspective, enforcement of laws as well as use of physical barriers to separate pedestrians and vehicles are perfectly respectable counter measures against pedestrian injuries. Some of the uproar is because the least lethal players in the urban drama, the pedestrians and bicyclists, feel they are being unfairly and illogically singled out. And, of course, other measures could and should be taken, including enforcement of speed limits, use of speed bumps, creation of walking streets in heavily congested areas, and stricter licensing of taxi drivers. But the public ridicule that has been heaped on the Mayor is a reminder of the critical role played by the social context in which environmental and behavioral interventions are launched.

POLLY E BIJUR Kennedy Center, Room 920 Albert Einstein College of Medicine, 1410 Pelham Parkway South, Bronx, NY 10461, USA

\section{British green papers highlight injury prevention}

In February 1998, the British government published two green papers (consultative policy statements) for England and Scotland: Our Healthier Nation and Working Together for a Healthier Scotland. These outline a strategic approach to public health that build on earlier target setting exercises that have met with limited success.
The green papers are especially noteworthy in that the New Labour administration explicitly recognises the strong association between poverty and poor health and the need to tackle the former (as well as lifestyle and behaviour) in the context of a comprehensive health promotion strategy.

For England, 12 year targets will be set to reduce mortality and morbidity in four priority areas: heart disease and stroke, accidents, cancer, and mental health (suicide). Targets do not feature prominently (although they are not ruled out) in the Scottish paper which, in addition to the above four areas, flags up a number of others, particularly teenage pregnancy and dental health.

The green papers have been broadly welcomed by public health professionals. Disappointment has been expressed however on two main counts. First, no targets have been set to monitor progress towards reducing the widening socioeconomic inequalities in health in the UK. Second, the proposed action seems weak on specific, sustained, and adequately resourced measures designed to make a major impact on the underlying social, environmental, and economic causes of ill health. Moreover, while the poorer health (including injury) record of the Scots is acknowledged, this is not backed up by a commitment to mount a proportionately more vigorous health improvement programme north of the border.

For injury prevention professionals, the statements are a mixed blessing. On the positive side, "accidents" have held their place as priority areas in both England and Scotland. Unfortunately, the writers of the green papers have clung to an outmoded and discredited terminology, have offered virtually no new ideas to address the injury problem, and have proposed targets that are likely to be met in the absence of any further policy initiatives whatsoever. Cynics might argue that therein lies the huge political appeal of the target setting exercise!

DAVID STONE The PEACH Unit, Department of Child Health, Yorkhill Hospital, Glasgow G3 8Sf Scotland, UK

\section{LETTERS TO THE EDITOR}

\section{Safety strategies}

Editor,- -Jan Shield is to be commended for rallying the troops in favour of "active" safety strategies, ${ }^{1}$ and most of her arguments in favour of education and enforcement would undoubtedly be valid in a developed country. However I would like to offer two contrasting viewpoints on the subject which are based primarily on personal observations related to the challenges of traffic safety confronting us in a cash strapped, developing country.

Firstly, in support of passive measures is the increasing strain placed on the human and financial resources essential to conceive and sustain education programmes and law enforcement, particularly in developing countries. As such, traffic calming measures are likely to be more effective than nothingsimply because there is no other affordable solution to undisciplined traffic flow on a 
particular thoroughfare. Twelve months ago, the community in which which I live opted for a system of restricted entry through the suburb to reduce to number of "rat runners" speeding along a particular route during the early morning. At the time the system was put in place, law enforcement of the system was sufficiently regular to be taken for granted, and to ensure an $86 \%$ reduction in traffic flow. Then, three months ago, the traffic department underwent severe rationalisation, and overtime for all officers was abolished. Now there is no enforcement of the restricted entry system and the "rat runners" are back in force. In retrospect, a passive measure such as closure of the main access road would obviously have been the better choice. In South Africa, where formal education is limping along on a shoestring budget, and law enforcement (for a multitude of reasons) is virtually non-existent in some areas, the option of passive safety measures must be placed high on any agenda - certainly where traffic safety is concerned.

Against what I have argued above is a word of caution. Just as active measures may fail, so may the too hasty adoption and construction of a passive device which is inappropriate for the identified purpose. Possibly because environmental modification may be the quickest and cheapest solution to an injury hazard-a form of instant gratification - the device too hastily chosen may fail dismally to counter that hazard simply because of a lack of adequate research into the hazard itself, or failure to consult expert opinion before firing up the cement mixer. Again, in South Africa, I notice a growing trend for traffic calming measures to be demanded by community groups, often in response to a spate of casualties in a residential area, or because a particular intersection has been identified as a "black spot". Lay people may go one step further and put pressure on a municipality to construct a specific kind of device, speed humps being particularly popular, although by no means a panacea where the hazard may be compounded by a complexity of factors of which vehicle speed is only one. Also, piecemeal engineering may simply divert a hazard elsewhere so that it becomes the problem of a neighbouring suburb instead.

The most effective passive strategies may simply require forward planning rather than hoping vainly that a "finger in the dyke" approach will plug the gaps later on. Resorting to an ad hoc solution reflects that town planners eschewed safety considerations from the outset and the attitude that condones such blinkered thinking must be discouraged.

There is currently a backlog of over two million subsidised houses in South Africa. These can be constructed either according to an inexpensive generic plan which creates lots of accommodation, and many attendant hazards, or by careful planning that can ensure that safety features are built into the scheme as a whole, for example sufficient recreational space and play areas, shorter streets, restricted access for through traffic, etc. In that effective, enduring passive safety measures do indeed require foresight, research, and careful consideration, these should not be either resorted to, or denigrated as a "cop out", or even worse, as a quick fix.

DAVID BASS Department of Paediatric Surgery, Red Cross War Memorial Children's Hospital, Rondebosch 7700, South Africa (e-mail:DAVEB@redxch.wcape.gov.za)
1 Shield J. Have we become so accustomed to being passive that we've forgotten how to be active? Inj Prev 1997;3:243-4

\section{Challenge of drowning prevention in low} and middle income countries

EDIToR,-We read the editorial on "The challenge of drowning prevention" with great interest. ${ }^{1}$ There is no doubt that drowning is a major but under recognised cause of premature loss of life and disability. This has been borne out by the Global Burden of Disease Study which highlights the scale of the problem, by region and by age and sex characteristics. ${ }^{2}$ It is worth examining their findings further.

At a worldwide level, Murray and Lopez estimated that drowning was responsible for about half a million deaths in 1990 and ranked 20th as a leading single cause of mortality, after road traffic accidents (9th), self inflicted injuries (12th), and violence (17th) as the other injury related causes. ${ }^{3}$ Mortality rates from drowning were highest for children under 5 in China, followed by countries belonging to the "other Asia and islands" region, and sub-Saharan Africa, with the lowest rates in the "established market economies" (EME).* In this age group, the mortality rate ratio between China and the EME was 13:1 in boys and 22:1 in girls.

The large degree of variation between the different regions in the study must belie an even greater variation, both between and within countries, given the different geography and populations. There is great diversity in the circumstances in which drowning occurs in these different areas. Whereas swimming pools, sailing, and water sports may be priority areas in the EME, in low income countries attention must need to be paid to drowning in streams, wells, dams, cisterns, and while fishing. ${ }^{14}$ Clearly there are a huge range of different environmental and behavioural circumstances. The obvious intervention to keep the child who cannot swim away from water must have a different interpretation in the different regions. Although swimming pools could be fenced in EME countries, the fencing of waterways would be impractical in countries where this runs into thousands of kilometres. This is not to say that there are no common approaches. As the editorial rightly points out, education about the risks, closer supervision, and training in resuscitation are important first steps which could be applied globally. Researchers also need to study the circumstances under which drowning occurs and the first aid and health care response, within countries and cross nationally. Data on good practice need to be collated so that appropriate interventions which are transferable to other low and middle income countries can be easily identified. Whatever the intervention there is an urgent need to get drowning higher on the agenda for policy makers and researchers.

*The Global Burden of Disease Study used the eight global regions identified by the World Bank for the World Development Report 1993 with similar levels of socioeconomic development, epidemiological homogeneity, and geographical contiguity: the EME, former socialist economies of Europe, India, China, other Asia and islands, sub-Saharan Africa, Latin America and the Caribbean, and the Middle East crescent (which includes North Africa, the Middle East, Pakistan, and the Central Asian republics of the former Soviet Union).

DINESH SETHI ANTHONY ZWI

Health Policy Unit,

London School of Hygiene and Tropical Medicine, Keppel Street, London WC1E 7HT, UK
1 Pless IB. The challenge of drowning prevention [Editorial]. Inj Prev 1997;3:237-9.

2 Murray CJL, Lopez AD. Global health statistics: a compendium of incidence, prevalence, and mortality estimates for over 200 conditions. Volume II. Cambridge: Harvard University Press, 1996.

3 Murray CJL, Lopez AD. Mortality by cause for the eight regions of the world: Global Burden of Disease Study. Lancet 1997;349:1269-76.

4 Celis A. Home drowning among preschool age Mexican children. Inj Prev 1997;3:252-6.

\section{Injuries in less industrialised countries}

EDITOR,-I read with interest the report by Mohan published in December. ${ }^{1}$ I agree that "Priorities for injury control have to be based on intelligent assessments of official statistics...". This is what prompted me to call attention to the improper use of the word "rate" as presented in the second paragraph, where the author writes "....the rate in India (8.6) is...." in reference to table 1 "Distribution of deaths as a percentage of regional total".

Rates and proportions (expressed as percentages) are different. A rate is the ratio of two different quantities (generally symbolised by the equation $a / b$ ) while a proportion is the result of dividing two quantities where the numerator forms part of the denominator (symbolised by the equation $\mathrm{a} /(\mathrm{a}+\mathrm{b})$ ). A proportion multiplied by 100 is a percentage.

Rates and proportions are not synonyms. It seems the author meant to say "percentage" and not "rate". This mistake could confuse those beginning in the field of epidemiology, prompting them to think that "percentage" and "rate" are synonymous: they are not.

ALFREDO CELIS

Public Health Department, CUCS, University of Guadalajara, Sierra Mojada \#950, Colonia Independencia, Centro Midico, 44242, Guadalajara, falisco, Mexico

1 Mohan D. Injuries in less industrialised countries: what do we know? Inj Prev 1997;3:241-2.

\section{BOOK REVIEW}

Target Risk: Dealing with the Danger of Death, Disease and Damage in Everyday Decisions. By Gerald J S Wilde. (Pp 234.) Toronto: PDE Publications, 1994. ISBN 0-9699-12404.

In Target Risk, Professor Gerald Wilde of Queen's University in Ontario, Canada assembles an impressive body of theory and evidence to support a provocative conclusion: the only effective strategy for achieving substantial and durable reductions in the rate of injury in a population is to increase people's desire to be safe and healthy. Traditional measures of injury preventionengineering, education, and enforcementare doomed to failure because they do not alter the "target levels of risk" that govern risk taking behaviors. The process of "risk homeostasis" will ultimately undermine all nonmotivational countermeasures, since people will alter behaviors to achieve an equilibrium between the overall amount of risk they perceive and their overall desired level of risk. The key to success, Wilde argues, is "expectationism": promoting people's interest in their future wellbeing in order to motivate adoption of smaller risk targets. 
Wilde is not arguing that people enjoy or seek risk of injury. Like behavioral decision analysts and economists, he postulates that people select or accept risk targets in order to achieve other desired ends in life. When safer highways are built, drivers trade some or all of the extra safety for faster travel speeds and more relaxation (and inattention) in driving. When road conditions deteriorate (due to ice or fog), people sense elevation in risk and respond by slowing down and driving with more care. Using variations on this adaptation theme, Wilde challenges the effectiveness of most mainstream injury prevention measures: seat belt laws, antilock brakes, traffic lights, driver training/education, crackdowns on drinking and driving, highway design improvements, motorcycle helmet laws, you name it! Even more provocatively, Wilde hints that any long term progress that might be made in fatal injury could be offset by increases in the risk of fatal diseases (since people's overall risk target is maintained).

Technical specialists will certainly find fault with Professor Wilde's handling of a variety of complex empirical questions. For example, I thought his discussion of the association between the business cycle and injury frequencies was fair and insightful, yet his assessment of the effectiveness of safety belt use laws was highly selective, one sided, and arguably deceptive. Professor Wilde also has a tendency to see risk homeostatic explanations behind all empirical anomalies Again, on safety belt use laws, Wilde notes that if belts are $50 \%$ effective in saving lives, and if belt use rates increased 50 percentage points following laws, why didn't laws cause an immediate $25 \%$ decline in occupant fatality counts? (Wilde is correct that few jurisdictions have experienced $25 \%$ reductions in fatalities after belt laws.) Aha, Wilde asserts, maybe drivers offset the benefit of the safety belts by taking more risks. Some alternative explanations that Wilde ignores are (a) the most crash prone drivers (for example, drunks and young males) may be least likely to comply with the law, (b) the $50 \%$ increase in use is an exaggeration, and even (c) the $50 \%$ effectiveness number may be biased upward (we once thought belts might be 60-90\% effective).

Yet I would urge specialists to overlook Wilde's handling of detailed technical matters because such focus can cause the reader to shortchange Wilde's overall message. It is a message that the field of injury prevention needs to hear. We spend remarkably little effort on bottom-up approaches to motivating safety (for example, incentives) and inordinate resources on top-down measures aimed at protecting people from their folly (for example, helmet laws and speeding controls). A deeper understanding of the motivational barriers that frustrate injury prevention measures is critical to the advancement of our field. Professor Wilde makes a lasting contribution by shedding some light on this neglected area.

This book has a length of 234 pages. It is comprehensive in topic coverage. The topics are as follows: the concept of homeostasis, compact theory of risk taking, theory of risk homeostasis, deductions and data, intervention by education, remedy by engineering, enforcement action, risk homeostasis in the laboratory, individual differences, and motivating for safety and health.

\section{$\overline{P E D N E T}$ PEDNET}

One of the strengths of the pedestrian e-mail network, PEDNET, is the diverse background of the participants. Last month, a physicist, Alan Streater (ads4@lehigh.edu), used his analytical skills to examine how major newspapers covered 42 motor vehicle pedestrian deaths. He termed his analysis "quick and dirty" but it provides insight into the quality of coverage.

He categorized the wording in the reports into neutral, slightly biased against the pedestrians (for example, pointing out twice that it was dark or that the pedestrian was not on a crosswalk), or very biased against pedestrians (for example, "darted out", "ran out into traffic", etc). He found the wording was mostly neutral in 26 out of $42(62 \%)$, partially biased in five cases $(12 \%)$, and clearly biased in 10 cases $(24 \%)$. In six cases $(14 \%)$ the report provided additional wording to excuse the driver, such as "it was raining and hard to see". There were no cases in which wording appeared to exonerate the pedestrian in any way.

Alan had a disturbing observation - that newspaper reporters obtain their understanding of the fatality from police reports. He sees the need for a more careful analysis of biased language in newspaper coverage and, perhaps more importantly, police reports. The consequences of this bias may be more than just public perception; this bias may also jeopardize the prosecution of dangerous drivers. He also recommended comparing interregional and international differences in bias. $\mathrm{He}$ also reported the coverage of charges filed. A driver was reported to be charged in only one case out of $42(2 \%)$. In all other cases $(98 \%)$ the police apparently did not even issue a traffic ticket to the driver at the scene of the crash or shortly thereafter. In six cases, the crash was reported to be still under investigation, implying there is still a chance that some of these drivers might be charged later. Two cases were hit and run, and in one case the driver died. This analysis closely matches Amy Lightstone's recent analysis of drivers who kill child pedestrians. She found that 214 out of 237 drivers were not cited $(90 \%) .{ }^{1}$ Can something be done to change this obviously dangerous situation?

Again, the diversity of PEDNET participants provides insight into addressing driver behavior. Osias Baptista Neto (techtran@ ouro.alcance.com.br) reported that Brazil has reduced casualties dramatically after a change in traffic law at the beginning of the year. The new laws recognize that vehicular homicide may be unintentional but none the less results from risky behavior. Killing another person in a traffic crash results in imprisonment for two to four years, and a suspension or revocation of the driving license. It increases the penalty by half for striking a pedestrian in a crosswalk or on the sidewalk (pavement). Hereports that preliminary data show a $70 \%$ drop in casualties in the major cities like Sao Paulo, Belo Horizonte, and Curitiba. His report illustrates the benefits of global comparisons of injury control efforts. Injury Prevention connects the English speaking world, but extra effort is required to reach beyond the barrier of differing language.

The barrier is especially significant with legal terms and concepts. However difficult to analyze, injury prevention specialists need to examine international differences in how legal systems treat motor vehicle injuries.

PETER JACOBSEN

PO Box 712433, Los Angeles,

CA 90071-7433, USA

1 Lightstone AS, Peek-Asa C, Kraus JF. Relationship between driver's record and automobile versus child pedestrian collisions. Inj Prev 1997;3:262-6.

\section{Correction}

We regret that a production error occurred in the March issue; this resulted in three addresses being omitted. The missing addresses are as follows:

- Charles Larson (Going international: what are the implications? p 4), Pediatrics, Epidemiology and Biostatistics, Montreal Children's Hospital, 2300 Tupper, Montreal, Quebec H3H 1P3, Canada.

- Robert W Platt (ANOVA, $t$ tests, and linear regression, p 52), McGill University/ Montreal Children's Hospital, 2300 Tupper, Montreal, Quebec H3H 1P3, Canada.

- Chester S Jones (Children and personal watercraft: injury characterisics and potential countermeasures, p 61), Health Sciences, University of Arkansas, 308 HPER Building, Fayetteville, AR 72701, USA.

\section{CALENDAR}

18-22 October 1998. Fourth International Symposium: Rural Health And Safety In A Changing World, Delta Bessborough Hotel, Saskatoon, Saskatchewan, Canada. Organized by the Centre for Agricultural Medicine, University of Saskatchewan in cooperation with the Canadian Coalition for Agricultural Safety and Rural Health, Committee on Occupational Health in Agriculture of the International Commission on Occupational Health, and others. This conference seeks to capture the emerging science of health, safety, and sustainability in agriculture and rural life, and to probe beyond these issues to address the thriving and survival issues of the future. In addition to abstracts from scientists, health care workers and others, abstracts are also invited from rural people with views on this topic. Further details: Fourth International Symposium: Rural Health and Safety in a Changing World, Centre for Agricultural Medicine, RUH, PO Box 120, Saskatoon, Saskatchewan S7N 0W8, Canada (e-mail: symposium.98@usask.ca, web site: www. usask.ca/medicine/agmedicine/symp98.html).

\section{Notice to authors: a new section Brief reports}

All editors would like to publish as many worthy papers as possible, with minimal delay. To facilitate this, in future, the journal will include a section entitled "Brief reports". These will be peer reviewed and when approved, publication will be expedited.

Please note: papers being submitted for this section should not exceed 1500 words. 